\title{
EL DERECHO A NO DECLARAR DE LAS VÍCTIMAS DE VIOLENCIA DE GÉNERO A LA LUZ DE LA DOCTRINA RECIENTE DEL TRIBUNAL SUPREMO*
}

\author{
María Luisa VILLAMARÍn LóPEZ \\ Profesora Titular de Universidad \\ Departamento de Derecho Procesal \\ y Derecho Penal Facultad de Derecho \\ Universidad Complutense de Madrid \\ mlvillamarin@ucm.es
}

\begin{abstract}
RESUMEN
La autora aborda en este artículo la doctrina que en los últimos años ha emanado del Tribunal Supremo en materia de dispensa para declarar de los testigos parientes (art. 416 LEC). En particular, se ocupa de analizar tres cuestiones especialmente relevantes: primera, la necesidad o no de informar sobre esta dispensa; segunda, si puede acogerse a ella quien formuló acusación, y, finalmente, el valor probatorio de las declaraciones sumariales prestadas por una víctima que luego decide no declarar en juicio oral.
\end{abstract}

Palabras clave: dispensa de declarar, art. 416 LECrim., violencia de género, protección de las víctimas.

\section{ABSTRACT}

The writer faces here recent years case law by the Supreme Court concerning the right to be on remand of relative witnesses (art. 416 of LEC). It particularly studies three major issues: first, the need or lack of need to be informed of such privilege; second, the possibility to enjoy such who launched the case, and finally last but not least, proof of Summonds by a victim who eventually does not speak in trial.

Keywords: privilege not to testify, art. 416 Criminal Procedural Law, gender violence, victim protection.

\section{ZUSAMMENFASSUNG}

Die Autorin beschäftigt sich in diesem Artikel mit der herrschenden Rechtsauffassung des Obersten Gerichtshofs der letzten Jahre, nach welcher Familienangebö-

* Este artículo recoge el contenido de la comunicación defendida oralmente el día 20 de junio de 2019 en el «II Congreso Hispano- Brasileño sobre Cuestiones actuales de la justicia penal», que tuvo lugar los días 17 a 21 de junio de 2019 en la Facultad de Derecho de la Universidad Complutense de Madrid. 
María Luisa Villamarín López El derecho a no declarar de las víctimas de violencia...

rige von ibrer Zeugenaussagepflicht (art. 416 LECrim.) entbunden sind. Insbesondere werden drei besonders relevante Fragen behandelt: erste, die Notwendigkeit, über die Möglichkeit der Befreiung von der Zeugenaussagepflicht zu informieren oder dies zu unterlassen; zweite, kann sich davon befreien lassen, wer die Anklage erhoben hat? und endlich, die Beweiskraft der Prozessaussagen von Opfern, die später bei der richterlichen Anbörung sich entschließen, nicht auszusagen.

Schlüsselwörter: befreiung von der Zeugenaussagepflicht, art. 416 LECrim., geschlechtsspezifische Gewalt, Schutz der Opfer.

SUMARIO: I. INTRODUCCIÓN.-II. LA DISPENSA DE DECLARAR EN EL ÁMBITO DE LA VIOLENCIA DE GÉNERO.-III. LA ÚLTIMA JURISPRUDENCIA DEL TRIBUNAL SUPREMO SOBRE EL ARTÍCULO 416 LECrim.-1. El alcance subjetivo de la dispensa.-2. La cuestión sobre la necesaria información de la dispensa: ¿es necesario siempre informar sobre la existencia de esta dispensa? Y, ¿qué ocurre si no se hace?.-3. El valor de la dispensa para quien formula acusación.-4. El valor probatorio de las declaraciones sumariales prestadas por una víctima que luego decide no declarar en juicio oral.-5. Valoración crítica.-IV. CONCLUSIONES.-V. BIBLIOGRAFÍA.

\section{INTRODUCCIÓN}

Frente a la general obligación de declarar que pesa sobre todo testigo (art. 410 LECrim.), la Ley de Enjuiciamiento Criminal española prevé una serie de salvedades, bien por razones de Estado, bien en atención al cargo que ostenta el testigo, bien por su incapacidad física o moral o bien por razones de parentesco. En este último caso, los parientes del acusado no se ven privados de la posibilidad de declarar en contra de su familiar sino que la Ley les exime del deber general, consagrando una suerte de privilegio familiar, que deja a su voluntad la decisión de si se abstienen o no de prestar testimonio respecto del acusado.

Este privilegio es reconocido en casi todos los códigos procesales penales y, de hecho, su previsión legal se ha reputado coherente con el régimen de las garantías procesales penales reconocidas a nivel europeo, habiendo declarado el Tribunal Europeo de Derechos Humanos en varias ocasiones su ajuste al art. $6 \mathrm{CEDH}$ (por ejemplo, en los asuntos Kostovsk, de 20 de noviembre de 1989; Windisch, de 27 de septiembre de 1990; Unterpertinger, de 24 de noviembre de 1986, e Isgro, de 19 de febrero de 1991). En nuestro país tiene naturaleza de derecho fundamental en tanto en cuanto está previsto expresamente en el art. $24 \mathrm{CE}$, y luego desarrollado por el art. 416 LECrim., con una redacción bastante deficiente. 
En opinión de la doctrina y de la jurisprudencia, varias son las razones que abogan por su reconocimiento: a) primera, la protección del acusado, considerando este derecho como una manifestación más del principio nemo tenetur; $b$ ) segunda, la defensa de la búsqueda de la verdad en el proceso penal, argumento empleado por la doctrina extranjera basándose en la experiencia de que la declaración de los familiares es generalmente falaz; c) tercera, la protección del testigo frente a un posible conflicto de conciencia o de intereses, ya que, de no existir esta dispensa, el testigo se encontraría en una encrucijada entre su deseo de no perjudicar al acusado y de preservar los secretos que le han sido confiados por él, su miedo a ser perseguido penalmente y su deber de colaborar con la Justicia, y, por último, d) el amparo de las relaciones de familia ${ }^{1}$.

\section{LA DISPENSA DE DECLARAR EN EL ÁMBITO DE LA VIOLENCIA DE GÉNERO}

Desafortunadamente, en los últimos años, quienes están haciendo más uso de esta dispensa, están siendo las víctimas de delitos cometidos en el ámbito familiar. Sirvan para ilustrar esta afirmación tres datos extraídos de la Memoria de la Fiscalía de 2018: el primero: en 2017, de 1.533 retiradas de la acusación registradas, 1.432 lo fueron porque la víctima se acogió a la dispensa del art. 416 LECrim.; segundo dato: la Fiscalía tuvo que retirar la acusación en el 58,5 por 100 de los procedimientos por falta de pruebas al haberse acogido la víctima a esta dispensa; $y$, tercer dato: gran parte de las víctimas de estos delitos, que fallecieron a manos de sus parejas, las habían denunciado pero el procedimiento se había paralizado por acogerse posteriormente a la dispensa, sin que, por tanto, hubieran podido adoptarse medidas de protección ${ }^{2}$. ¿Y esto por qué? Porque, desgraciadamente, es muy habitual que cuando el familiar en cuestión es la víctima del investigado su declaración suela ser la única prueba con la que se cuenta para poder conocer los hechos y, por tanto, el silencio de la víctima en el proceso obliga a los tribunales a dejar impunes a los culpables, con sentencias absolu-

${ }^{1}$ Vid. sobre esta cuestión R. Castillejo Manzanares, «Denuncia y dispensa del deber de declarar», en Violencia de género y Justicia, Santiago de Compostela, Servicio de Publicaciones de la USC, núm. 203, pp. 549-580, y M. L. VILLAMARÍn LóPEZ, «El derecho de los testigos parientes a no declarar en el proceso penal», Indret, núm. 4 (2012), pp. 9 y ss.

2 Vid. Capítulo III.1 de la Memoria de la Fiscalía General del Estado de 2018 (bttps:// www.fiscal.es/memorias/memoria2018/FISCALIA_SITE/index.html). 
torias por falta de pruebas que, encima, refuerzan a los maltratadores a la vez que debilitan a sus víctimas.

En mi opinión, en este contexto de violencia intrafamiliar los motivos de la dispensa a los que antes aludíamos pierden su valor: cuando se cometen estos delitos entiendo que no hay ocasión de proteger dicha armonía o paz familiar, puesto que esta quiebra automáticamente como consecuencia del acto violento cometido por el acusado frente a uno de los integrantes del núcleo familiar. Tampoco opera en puridad el argumento de la existencia del conflicto de intereses o de conciencia ya que, si observamos con cierta profundidad, lo que normalmente subyace al silencio del familiar agredido no es la obligación ética o moral de guardar un secreto o de no revelar informaciones confidenciales de la familia sino que normalmente lo que está detrás de su indecisión suele estar estrechamente ligado a las consecuencias del hecho violento: el miedo a las represalias, a que se repitan hechos análogos, a quedarse sin el apoyo económico del cónyuge o, incluso, a veces la esperanza de que éste se arrepienta, cambie y todo se arregle. En palabras de la Audiencia Provincial de Castellón de 20 de diciembre de 2006, este silencio en no pocos casos «sólo es la muestra de la continuación del sometimiento padecido».

\section{LA ÚLTIMA JURISPRUDENCIA DEL TRIBUNAL SUPREMO SOBRE EL ARTÍCULO 416 LECRIM. ${ }^{3}$}

Preocupado por las discrepancias en la aplicación del art. 416 LECrim., el Tribunal Supremo ha desarrollado en los últimos años una ardua labor interpretativa para clarificar su interpretación en este contexto. En concreto, ha despejado las siguientes cuatro cuestiones:

a) El alcance subjetivo de la dispensa.

b) La cuestión sobre la necesaria información de la dispensa.

c) El valor de la dispensa para quien formula acusación.

d) Por último, el valor probatorio de las declaraciones sumariales prestadas por una víctima que luego decide no declarar en juicio oral.

\footnotetext{
3 Sobre esta reciente jurisprudencia, puede consultarse también A. RoDRíGUEZ ÁlvarEZ, «Dispensa del deber de declarar y violencia de género: el enésimo capítulo», en A. FigueRUElo BurRieza y M. DEL Pozo Pérez (dirs.), Retos actuales para la erradicación de la desigualdad y la violencia de género, Valencia, Tirant lo Blanch, 2019, e ÍD., «¿Hacia dónde camina la dispensa del deber de declarar? Un breve comentario a propósito del Acuerdo de 24 de abril de 2013 del Pleno no Jurisdiccional de la Sala Segunda del Tribunal Supremo», Revista de Derecho y Proceso Penal, núm. 33 (2014), pp. 21-30.
} 


\section{El alcance subjetivo de la dispensa}

El art. 416 LECrim. adoptó una solución intermedia a la hora de delimitar los parientes que pueden acogerse a esta exención; de hecho, no se refiere únicamente a los cónyuges, como el derecho inglés, sino que incluye también a los parientes más próximos, aunque con un alcance más limitado que los ordenamientos alemán e italiano, que amplían este privilegio incluso a los parientes del tercer grado de consanguinidad (esto es, a tíos y sobrinos), y que el francés, que lo reconoce también a todos los afines del mismo grado que los consanguíneos. Así, incluye a los padres e hijos, así como a los abuelos y nietos, a los cónyuges (y quienes se hallen en una situación análoga, a quienes se incluyó en la reforma de la LECrim. operada por la Ley 13/2009, de 3 de noviembre) y a los hermanos.

El Tribunal Supremo ha clarificado estos últimos años dos cuestiones sobre las que no existía una posición doctrinal del todo pacífica.

Tras años de debate sobre la necesidad o no de que, para que operara esta dispensa, subsistiera la convivencia matrimonial o more uxorio en el momento del proceso (así, por ejemplo, en SSTS 134/2007, de 22 de febrero, y 1010/2012, de 21 de diciembre, y Circular de la FGE 6/2011), el Tribunal Supremo puso fin a esta polémica en su Acuerdo de 24 de abril de 2013 en el sentido siguiente: se exceptúa de la dispensa «la declaración por hechos acaecidos con posterioridad a la disolución del matrimonio o cese definitivo de la situación análoga de afecto». Por tanto, el Tribunal Supremo extiende el privilegio aún cuando ya no esté constante el matrimonio en relación con los hechos acaecidos durante su vigencia ya que aprecia que, aunque no esté ya en juego la solidaridad familiar, sí lo está la intimidad.

En segundo lugar, aclara que la dispensa no está supeditada a la mayoría de edad y, por tanto, que los menores con suficiente madurez podrán acogerse a ella (SSTS 209/2017, de 28 de marzo, y 205/2018, de 25 de abril). Incluso, en el Pacto de Estado sobre Violencia de Género de $2019^{4}$ se plantea ampliar su aplicación a menores que no sean hijos del maltratador siempre que, valoradas las circunstancias, el juez aprecie su oportunidad.

\footnotetext{
${ }^{4}$ Vid. http://www.violenciagenero.igualdad.mpr.gob.es/pactoEstado/home.htm.
} 


\section{La cuestión sobre la necesaria información de la dispensa: $¿$ es necesario siempre informar sobre la existencia de esta dispensa? $\mathrm{Y}$, ¿qué ocurre si no se hace?}

Especialmente desde 2008 el Tribunal Supremo ha dejado claro que es obligatorio advertir a los testigos víctimas sobre la existencia de este privilegio familiar de no declarar, tanto en sede policial, como durante la instrucción y el juicio oral (STS 49/2018, de 30 de enero y 13/2009, de 23 de enero), debiendo reputarse nulas las declaraciones obtenidas omitiendo esta exigencia. Argumentaba el Tribunal a este respecto que nadie puede renunciar a lo que no conoce, por lo que es preciso informar a la víctima sobre este derecho para garantizar que realmente decide declarar voluntariamente, ya que si finalmente lo hace, queda obligado a decir verdad como cualquier otro testigo.

Con todo, la jurisprudencia ha considerado que puede prescindirse de esta información «en algunos casos de denuncia espontánea» (STC 94/2010, de 15 de noviembre): esto es, cuando el sujeto no es llamado a declarar como testigo sino que voluntariamente decide acudir a las autoridades a poner en conocimiento unos hechos que le afectan.

\section{El valor de la dispensa para quien formula acusación}

El Acuerdo del Tribunal Supremo de 24 de abril de 2013 al que antes nos hemos referido dejó fuera de la dispensa los «supuestos en que el testigo esté personado como acusación en el proceso». Como luego tuvo oportunidad de explicar el Tribunal, con esto se pretendía impedir una práctica «contraria a los propios actos» ya que se entendía que resultaba «contradictorio e incongruente» el hecho de permitir «acogerse al art. 416 a quien simultáneamente enarbola una petición de condena por los hechos a cuyo esclarecimiento rehúsa contribuir. Es fraudulento activar los mecanismos de la Administración de Justicia y al mismo tiempo obstaculizar su realización. Puede ejercitar su derecho a reclamar la condena; pero en ese caso no puede regatear al Estado, cuya tutela impetra, los medios para poder acoger su pretensión. Esa postura esquizofrénica e incongruente es la repudiada por aquel acuerdo» . Este Acuerdo de 2013 dio lugar a algún pronunciamiento que iba algo más allá, entendiendo que alcanzaba a estas víctimas-acusadores no solo para ese momento sino tam- 
bién para el futuro. Esto es, que quien formuló acusación se veía ya privado de la dispensa incluso en el futuro si decidía retirarse del proceso (STS 449/2015, de 14 de julio) ${ }^{5}$.

Pues bien, la cuestión fue clarificada años más tarde por el mismo Tribunal en su Acuerdo de 23 de enero de 2018, en el sentido siguiente:

«No queda excluido de la posibilidad de acogerse a tal dispensa (416 LECrim.) quien, habiendo estado constituido como acusación particular, ha cesado en esa condición» ${ }^{6}$.

Varias razones abogaron por esta solución: primera, que, dado que esta dispensa constituye un derecho constitucional, no cabe que los tribunales lo recorten con una interpretación restrictiva sin un «fundamento claro, preciso e indiscutible»: segunda, que «este Tribunal no puede erigirse en legislador inventando excepciones donde la ley no las prevé y afectando así, sin previa interpositio legislatoris a la generalidad con que el derecho está consagrado a nivel constitucional»; tercera, que la contradicción que se pretende evitar si un acusador quisiera esgrimir a la vez esta dispensa, ya no se aprecia cuando el sujeto ha renunciado a esa pretensión: «No se aprecia entonces nada en sí contradictorio; solo un cambio de postura, de opinión o de estrategia o una reordenación de sus preferencias, decisiones todas ellas que el derecho debe respetar, desde el momento en que ningún particular está obligado a formular acusación». Y, por último, porque no sería aceptable una renuncia de futuro a este privilegio: «no cabe la renuncia proyectada al futuro; por muy informada que sea esa renuncia» (STS 205/2018, de 25 de abril).

\section{El valor probatorio de las declaraciones sumariales prestadas por una víctima que luego decide no declarar en juicio oral}

Aunque sobre este punto la jurisprudencia del Tribunal Supremo había mantenido una posición pacífica, no lo era tanto en las Audiencias Provinciales ni el criterio defendido por la Fiscalía General del Estado, que había

5 Pese a esta Sentencia del Supremo, las Audiencias Provinciales seguían manteniendo el criterio contrario. Vid., por ejemplo, en SSAP de Madrid 527/2016, de 20 de julio, de Tarragona 281/2016, de 18 de julio, y de Gerona 443/2016, de 6 de julio).

6 Tras este Acuerdo, se ha aplicado esta doctrina, entre otras, en SSAP de Madrid 364/2018, de 9 de mayo, y 507/2018, de 13 de julio. 
postulado que, siempre que fuera posible, cuando durante el juicio oral las víctimas hubiera permanecido en silencio, se trataran de introducir sus declaraciones sumariales en el juicio oral a través del cauce previsto en el art. 730 LECrim. ${ }^{7}$ Para no dejar ningún asomo de duda, el citado Acuerdo de 2018 cerró toda posible polémica sobre esta cuestión, sosteniéndose lo siguiente:

«El acogimiento, en el momento del juicio oral, a la dispensa del deber de declarar establecida en el art. 416 de la LECrim., impide rescatar o valorar anteriores declaraciones del familiar-testigo aunque se hubieran efectuado con contradicción o se hubiesen efectuado con el carácter de prueba preconstituida».

El Supremo fundamenta su posición en que en estos casos no se da el presupuesto legal básico para que opere el art. 730 LECrim.: la imposiblidad jurídica para declarar y, por tanto, entiende que «subsumir estos supuestos en este precepto supone desvirtuar el precepto, apartarse de su fundamento, desnaturaliza su condición de excepción y choca contra el legítimo ejercicio de la dispensa de declarar contra un pariente porque se opone al resultado que con ese ejercicio se pretende»; y añade: «por irreproducible a los efectos del art. 730 debe entenderse lo que ni siquiera es posible por el propio carácter definitivo de las causas que lo motivan; algo que no es predicable del testigo que acudiendo al Juicio Oral opta allí y en ese momento por ejercitar el derecho o no a declarar que la Ley le atribuye» (STS 205/2018, de 15 de abril, que cita, entre otras, en este sentido, SSTS 486/2016, de 7 de junio; 703/2014, de 29 de octubre, y 459/2010, de 19 de mayo).

\section{Valoración crítica}

Pues bien, llegados a este punto podemos preguntarnos: ¿ha mejorado con esta doctrina del Supremo la protección de las víctimas?

En mi opinión la respuesta es negativa. Si bien es cierto que con esta doctrina se ha blindado mejor este derecho fundamental al silencio a favor de los familiares y se han clarificado muchas de las cuestiones más polémi-

7 Vid., por ejemplo, en este sentido la Circular 6/2011, de 2 de noviembre, sobre criterios para la unidad de actuación especializada del Ministerio Fiscal en relación con la violencia sobre la mujer. 
cas, no parece que esto vaya a mejorar la persecución de los delitos de violencia de género; antes al contrario, esta lectura tan favorable al reconocimiento de esta dispensa a las víctimas a buen seguro dará lugar a un mayor número de autos de sobreseimiento o de sentencias absolutorias por falta de pruebas. Probablemente nada distinto le era exigible al Supremo con la legislación vigente en el mano, pero sí parece que estas tesis son reveladoras de la necesidad urgente de modificar esta materia.

\section{CONCLUSIONES}

Concluyo esta comunicación así formulando brevemente dos propuestas de lege ferenda de cara a una posible reforma del régimen de privilegios familiares en la prueba de testigos en el proceso penal.

Primera. Considero que debería excluirse de su ámbito subjetivo de aplicación a los parientes cuando sean víctimas de alguno de los delitos comprendidos en el art. 173.2 CP. Con ello, se aliviaría la losa que actualmente pesa sobre la espalda de las víctimas de estos delitos. Esta solución, nueva en nuestro ordenamiento, no lo es en derecho comparado. Sirvan como ejemplo, en el ámbito europeo el art. 199.1 CPP italiano, que obliga a declarar a los parientes que denuncien o se querellen o si son víctimas de delito y el art. 80 (1) de la Police and Criminal Evidence Act del Reino Unido, que no reconoce este privilegio a las víctimas de delitos cometidos en el ámbito familiar, y en el ámbito de americano, el art. 242 del Código Procesal Penal Federal argentino o el art. 206 del Código Procesal Penal Brasileño que, pensando casi con seguridad en estos supuestos, levanta la dispensa de forma muy oportuna cuando, señala, «no fuera posible de otro modo obtenerse o integrarse la prueba del hecho o de sus circunstancias».

No se nos oculta que esta solución también comporta ciertos riesgos para la víctima, que, en principio, se vería obligada a declarar como testigo bajo amenaza de falso testimonio, si bien estos posibles efectos perversos de esta previsión pueden mitigarse con soluciones como la arbitrada en el proceso inglés en el que los fiscales tienen la consigna de retirar la acusación antes del juicio si la víctima está decidida a no declarar. De hecho, no hay prácticamente ningún caso de condena por falso testimonio registrado en sus estadísticas.

Segunda. La segunda propuesta, que formulo con carácter eventual, consiste en la reforma del art. 730 LECrim. en el sentido de que, si el testigo decidiera finalmente no declarar en el juicio oral, se pue- 
dan leer sus declaraciones prestadas en fases anteriores, siempre, claro está, que se hayan respetado en aquel momento las garantías de defensa y contradicción y se le hubiera informado oportunamente de que esto podía ocurrir $^{8}$. De hecho, desde el Observatorio de Violencia se ha propuesto recientemente ${ }^{9}$ la grabación de la primera declaración de la víctima para luego reproducirla en juicio, evitando así los efectos de la retractación.

\section{BIBLIOGRAFÍA}

Castillejo Manzanares, R.: «Denuncia y dispensa del deber de declarar», en Violencia de género y Justicia, Santiago de Compostela, Servicio de Publicaciones de la USC, núm. 203, pp. 549-580.

Fuentes Soriano, O.: «Los procesos por violencia de género. Problemas probatorios tradicionales y derivados del uso de las nuevas tecnologías», Revista General de Derecho Procesal, núm. 44 (2018).

Memoria de la Fiscalia General del Estado de 2018: https://www.fiscal.es/memorias/memoria2018/FISCALIA_SITE/index.html.

Rodríguez Álvarez, A.: «¿Hacia dónde camina la dispensa del deber de declarar? Un breve comentario a propósito del Acuerdo de 24 de abril de 2013 del Pleno no Jurisdiccional de la Sala Segunda del Tribunal Supremo», Revista de Derecho y Proceso Penal, núm. 33 (2014), pp. 21-30.

- «Dispensa del deber de declarar y violencia de género: el enésimo capítulo», en A. Figueruelo Burrieza y M. Del Pozo Pérez (dirs.), Retos actuales para la erradicación de la desigualdad y la violencia de género, Valencia, Tirant lo Blanch, Ars Iuris, 2019.

Rodríguez LanZ, J. L.: «Sería inconstitucional negar a un víctima de violencia de género el ejercicio de un derecho a no declarar en contra del agresor?», Diario La Ley, núm. 9064 (2017).

Urbano Castrillo, E.:, «La dispensa del deber de declarar (art. 416 LECrim.)», Revista Aranzadi Doctrinal, núm. 7 (2018), p. 13.

Villamarín LóPEZ, M. L.: «El derecho de los testigos parientes a no declarar en el proceso penal», Indret, núm. 4 (2012).

\footnotetext{
${ }^{8}$ En el mismo sentido, entre otros, O. Fuentes Soriano, «Los procesos por violencia de género. Problemas probatorios tradicionales y derivados del uso de las nuevas tecnologías», Revista General de Derecho Procesal, núm. 44 (2018), p. 13, E. Urbano Castrillo, «La dispensa del deber de declarar (art. 416 LECrim.)», Revista Aranzadi Doctrinal, núm. 7 (2018), p. 13, y J. L. RodRíGUEZ LAINZ, «Sería inconstitucional negar a un víctima de violencia de género el ejercicio de un derecho a no declarar en contra del agresor?», Diario La Ley, núm. 9064 (2017), pp. 16 y 17.

9 http://www.violenciagenero.igualdad.mpr.gob.es/pactoEstado/home.htm.
} 